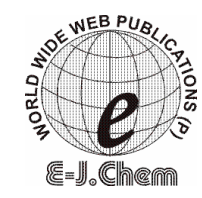

http://www.e-journals.net
ISSN: 0973-4945; CODEN ECJHAO

E-Journal of Chemistry

Vol. 5, No.4, pp. 864-871, October 2008

\title{
Enhancement of Lipase Enzyme Activity in Non-Aqueous Media through a Rapid Three Phase Partitioning and Microwave Irradiation
}

\author{
N. SAIFUDDIN* and A.Z. RAZIAH \\ Chemistry Unit, Department of Engineering Sciences, \\ College of Engineering, Universiti Tenaga Nasional, \\ 43900 Serdang, Selangor, Malaysia. \\ saifuddin@uniten.edu.my; Ph: 603-89287285
}

Received 12 March 2008; Revised 2 May 2008; Accepted 1 July 2008

\begin{abstract}
Three phase partitioning is fast developing as a novel bio-separation strategy with a wide range of applications including enzyme stability and enhancement of its catalytic activity. pH tuning of enzyme is now well known for use in non-aqueous systems. Tuned enzyme was prepared using a rapid drying technique of microwave dehydration (time required around 15 minutes). Further enhancement was achieved by three phase partitioning (TPP) method. With optimal condition of ammonium sulphate and $t$-butanol, the protein appeared as an interfacial precipitate between upper $t$-butanol and lower aqueous phases. In this study we report the results on the lipase which has been subjected to $\mathrm{pH}$ tuning and TPP, which clearly indicate the remarkable increase in the initial rate of transesterification by 3.8 times. Microwave irradiation was found to increase the initial reaction rates by further 1.6 times, hence giving a combined increase in activity of about 5.4 times. Hence it is shown that microwave irradiation can be used in conjunction with other strategies (like $\mathrm{pH}$ tuning and TPP) for enhancing initial reaction rates.
\end{abstract}

Keywords: pH tuned enzyme, Enzyme in organic media, Lipase-Candida rugosa, Three phase partitioning, Microwave irradiation, Microwave drying.

\section{Introduction}

Enzymes or biocatalysts are biomolecules that act on substrates specifically and ultimately cause transformation/ conversion of substrates to products. The advantages of biocatalysts 
over inorganic catalysts include; high specificity, high rate of reaction, non-toxicity, biodegradability, reproducibility under normal laboratory conditions, mild conditions of $\mathrm{pH}$, temperatures and pressure ${ }^{1}$. One group of industrially useful enzymes is the lipases, (glycerol ester hydrolases E. C. 3. 1. 1. 3). Lipases are able to catalyze hydrolysis reaction of ester in aqueous media and esterification/transesterification reaction in the organic media. The defining characteristic of lipases is the phenomenon named "interfacial activation": the enzymatic activity of lipase is greatly increased when the substrate is presented at an oilwater interface, a phenomenon that is due to the unique structural characteristics of this class of enzymes ${ }^{2-3}$. Enzyme stability is dictated by its three-dimensional configuration. Lipases have a helical unit called "lid" which shields the active site. Lipases typically possess a hydrophobic surface, often containing a 'lid' region associated with the active site ${ }^{4}$ (Figure 1), and it is believed that this surface associates with the hydrophobic phase at the interface between hydrophilic and hydrophobic fluids. The interfacial activation of lipase results primarily from conformation changes of the "lid" surrounding the active site in response to the solvent conditions. This exposes the active site and provides a hydrophobic surface for interaction with the lipid substrate; hence substrate accesses to active site more freely ${ }^{2}$.

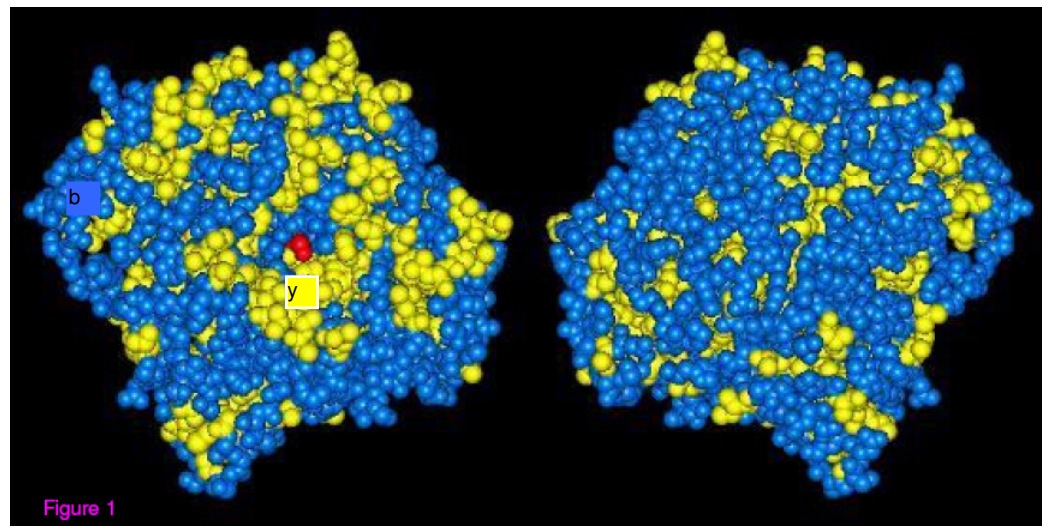

Figure 1. Candida rugosa lipase as visualized in Accelerys Viewer Lite 4.2. Yellow indicates hydrophobic amino acids; Blue all other amino acids, and Red- the active site. Note the hydrophobic ring around the active site. (RCSB Protein Data Bank) $)^{5}$.

The use of enzymes in organic media (with low water content) has been one of the most exciting facets of research in recent times. Simultaneously, there have been concerns about the relatively low catalytic power observed under such non-aqueous conditions as compared to aqueous buffer and hence stabilization of enzymes is currently the subject of considerable attention ${ }^{1}$. The decreased molecular flexibility of the enzyme powder suspended in low water media has been partly shown to account for the low catalytic activity of enzymes under low water conditions. In fact, this low activity originates in the rigidity of protein molecules taking place during lyophilization drying which removes water molecules that were H-bonded to many surface residues. The "tuning up" of an enzyme's pH is a particularly important step in non-aqueous enzymology, and it is often accomplished while the enzyme is dissolved in a buffer prior to dehydration (usually by lyophilization) before suspension in the organic solvent of choice ${ }^{6}$. The correct protonation state of side chains of amino acid residues of enzymes is important. It is also well documented that, once in an organic solvent, most enzymes "remember" their ionization state from the aqueous solution they were dissolved in prior to dehydration. This is often referred to as "the enzyme's pH 
memory"7 ${ }^{17}$ Hence $\mathrm{pH}$ tuning results in higher rates in organic solvents. It is well established that the dehydration step, required before introducing an enzyme to the organic medium (and usually achieved by lyophilization), induces structural perturbation in the enzyme's secondary structure. It is well known that enzyme catalysis in these non-natural media offers some advantages over that in natural-aqueous environment ${ }^{8}$. In conventional enzymology (in aqueous media), rehydration reverses much of the structural damage during lyophilization. In nonaqueous enzymology, this becomes very crucial and is now considered as largely responsible for the low $k_{\text {cat }} / \mathrm{Km}$ of enzymes in nearly anhydrous media ${ }^{9-11}$. On the other hand, when used in low water-containing organic solvents, rehydration is not possible and the structure remains highly thermostable.

Recently, it was observed that three phase partitioning (TPP) of proteinase K resulted in enhancement of its catalytic power in aqueous buffers ${ }^{12}$. The process, originally described as a bio-separation strategy, consists of adding less than 'salting out' amount of ammonium sulphate and $t$-butanol to the aqueous solution of the enzyme. The X-ray diffraction pattern of proteinase K, after being subjected to TPP, showed unusually high 'B-factor', signifying overall increase in the flexibility of the protein molecule ${ }^{12}$. Three phase partitioning (TPP) shows sufficient promise for obtaining enzymes with better catalytic power in both aqueous and non-aqueous media and appears to be a useful method to improve the purity and efficiency of enzymes. The enzyme, after being subjected to TPP, showed greater activity in organic solvents. It was hoped that such a TPP-treated enzyme with a more flexible structure would have higher catalytic efficiency ${ }^{13}$.

The use of microwaves irradiation has become a fairly routine technique to enhance reaction rates of chemical reactions. One does not have to worry about thermal inactivation while using microwaves if the medium is nearly anhydrous. Enhancements of reaction rates in the microwave-assisted esterification were observed with un-tuned, $\mathrm{pH}$-tuned and salt-activated enzymes $^{14}$. In this study, we will employ microwave irradiation as a dehydration method (instead of lyophilization) for $\mathrm{pH}$ tuning. The tuned enzyme will be further subjected to three phase partitioning (TPP) and microwave irradiation to further enhance its catalytic activity.

\section{Experimental}

\section{Materials}

Lipase (Candida rugosa) was purchased from $\mathrm{HmbG}$ Chemicals. Tris- $\mathrm{HCl}$ was a product of CalBiochem. Ammonium sulphate and $t$-butanol were purchased from Merck. $p$-Nitrophenyl palmitate (4-nitrophenyl palmitate) and $p$-nitrophenol (4-nitrophenol) were purchased from Sigma-Aldrich Corporation. The solvents were purchased from Aldrich in the anhydrous form (Sure/Seal bottles, water content below 0.005\%). All other chemicals were of analytical grade. Microwave irradiation were carried out in a domestic microwave oven (National Model NN-GD 576M). Aqua Lab model series 3, water activity meter was used to determine the water activity.

\section{Procedures}

\section{pH- tuned enzyme}

The native, lipase enzyme $(200 \mathrm{mg}$ ) was dissolved in $10 \mathrm{~mL}$ of $0.02 \mathrm{M}$ Tris- $\mathrm{HCl}, \mathrm{pH} 7.8$ and then subjected to several short bursts of microwave irradiation at frequency of $2.45 \mathrm{GHz}$, at power output of about $100 \mathrm{~W}$ for 10 seconds. The sample was then cooled. This ramp/cool cycle was repeated 12-15 times until the sample was dry. This was referred to as pH-tuned enzyme. 


\section{Three phase partitioning (TPP) and $p H$ tuning of enzyme}

Lipase solution $(9 \mathrm{~mL}, 3 \mathrm{mg}$ solid native enzyme $/ \mathrm{mL}$ of $0.02 \mathrm{M}$ Tris- $\mathrm{HCl}, \mathrm{pH} 7.8$ ), was saturated with $50 \%(\mathrm{w} / \mathrm{v})$ solution of ammonium sulphate. This was followed by addition of $18 \mathrm{~mL}$ of $t$-butanol $(1: 2, \mathrm{v} / \mathrm{v}$, ratio of the enzyme solution to $t$-butanol). The solution was vortexed and allowed to stand at $25^{\circ} \mathrm{C}$ for $1 \mathrm{~h}$. The solution was then centrifuged $(2000 \mathrm{x} g$, $10 \mathrm{~min}$ ). The lower aqueous and upper organic layers were separated using a pasteur pipette. The interfacial precipitate was dissolved in $5 \mathrm{~mL}$ of $0.02 \mathrm{M}$ Tris- $\mathrm{HCl}, \mathrm{pH} 7.8$, and dialyzed against the same buffer ${ }^{13}$ for $16 \mathrm{~h}$ at $4^{\circ} \mathrm{C}$. After being dialyzed, the enzyme solution was subjected to microwave irradiation for 10 second at frequency of $2.45 \mathrm{GHz}$, a power output of about $100 \mathrm{~W}$. The sample was then cooled. As mentioned previously, this $\mathrm{ramp} / \mathrm{cool}$ cycle was repeated 12-15 times until the sample was dry. This was referred to as TPP-pH tuned lipase.

\section{Assay for lipase activity using p-nitrophenylpalmitate (pNPP) as substrate}

The activity of lipase in low water organic media was monitored by following the hydrolysis of $p$-nitrophenyl palmitate in water-saturated $n$-heptane (using varying water saturation from 0 to $1.0 \%$ water activity, $\left.\mathrm{a}_{\mathrm{w}}\right)^{15}$. The release of $p$-nitrophenol yields a yellow colour which was measured spectrophotometrically at $410 \mathrm{~nm}\left(25^{\circ} \mathrm{C}\right)$.

\section{Lipase assay reagent}

Reagent A consisted of $0.0667 \mathrm{~g}$ of Gum Arabic (Acacia tree) dissolved in Tris-HCl buffer (12 mL, $250 \mathrm{mM}, \mathrm{pH} 7.8$ ) containing $48 \mathrm{~mL}$ of distilled water. Thereafter $0.267 \mathrm{~g}$ of sodium deoxycholate was added and dissolved in the solution. Reagent B consisted of either $24 \mathrm{mg}$ of $p$-nitrophenyl palmitate dissolved in $8 \mathrm{~mL}$ propan-2-ol at $37^{\circ} \mathrm{C}$. Reagent $\mathrm{B}(1 \mathrm{~mL})$ was added to $9 \mathrm{~mL}$ of reagent $\mathrm{A}$ with rapid stirring for approximately 20 seconds $^{16}$.

Enzyme $(10 \mathrm{mg})$ was added to $900 \mu \mathrm{l}$ of the lipase assay reagent and the reaction mixture was incubated at $40^{\circ} \mathrm{C}$ for $10 \mathrm{~min}$. The reaction was terminated by adding $2 \mu \mathrm{L}$ of $0.5 \mathrm{M}$ EDTA. The activity was assayed by detecting the product, $p$-nitrophenol, spectrophotometrically at $410 \mathrm{~nm}$ with a GENESYS 10 UV-Vis spectrophotometer (Thermo-Fisher) at $25^{\circ} \mathrm{C}$ against an enzyme-free blank. The molar extinction coefficient of $p$-nitrophenol at $\mathrm{pH} 7.8$ was calculated as $15.1 \mathrm{M}^{-1} \mathrm{~cm}^{-1}$. One unit of enzyme activity was defined as the quantity of enzyme required to liberate one $\mu$ mole of $p$-nitrophenol per minute under the above conditions.

\section{Microwave irradiation of lipase catalyzed reaction}

Identical amounts of enzyme and lipase assay reagent were taken as mentioned above and placed in a glass vessel. The whole reaction mixture was placed in the microwave oven and irradiated for 10 second at frequency of $2.45 \mathrm{GHz}$, a power output of about $100 \mathrm{~W}$. After the irradiation, the vessel was quickly removed; the actual temperature of the sample reaction mixture was measured with a handheld non-contact infra-red thermometer (Omegascope, USA) and was found to be around $40^{\circ} \mathrm{C}$. The reaction was terminated by adding $2 \mu \mathrm{L}$ of $0.5 \mathrm{M}$ EDTA. The activity was assayed by detecting the product, $p$-nitrophenol, spectrophotometrically at $410 \mathrm{~nm}$ at $25^{\circ} \mathrm{C}$ against an enzyme-free blank which was also subjected to microwave treatment.

\section{Results and Discussion}

In recent years, there has been growing interest in developing techniques for modification of lipases, in order to use them more economically and efficiently on large industrial scale. 
While enzymes are being increasingly used in organic solvents for a variety of applications, their low activity continues to be of major concern ${ }^{10}$. The role of lyophilization for obtaining enzyme preparations for non-aqueous enzymology is rather recent. $\mathrm{pH}$ tuning and $\mathrm{pH}$ memory are observation for which clear rationalization is now available. The correct protonation state of side chains of amino acid residues of enzymes is important in nonaqueous media as well. The dehydration step induces structural perturbation in the enzyme's secondary structure and these changes offers some advantages such as prevention of autolysis (in case of proteases) and increased thermo stability ${ }^{8}$. Hence $\mathrm{pH}$ tuning results in higher rates in organic solvents ${ }^{7,17}$. In this study $\mathrm{pH}$ tuning of the lipase enzyme was done using $0.02 \mathrm{M}$ Tris-HCl buffer, $\mathrm{pH}$ 7.8. However instead of lyophilizing the enzyme, we used several short burst of microwave irradiation in cycles of 10 second each. After 15-20 cycle of ramp/cool treatment the enzyme solution was dry. This was known as the 'tunedenzyme'. Our experiments have shown that it takes only between 8-15 minutes to prepare the tuned enzyme. This drastically reduces the time taken to prepare tuned enzymes as compared with the current practice which requires overnight lyophilization.

While lipases have been employed in aqueous media as well for the production of free fatty acids, their (transesterification) reactions in low water containing organic solvents have found wide applications in synthesis and resolutions of esters, acids and alcohols ${ }^{18,}{ }^{19}$. Hence, the focus of the work was to evaluate the $\mathrm{pH}$-tuned lipase and TPP-treated plus $\mathrm{pH}$ tuned lipase for transesterification with microwave irradiation in organic solvents containing low amounts of water. (Water activity, $a_{\mathrm{w}}$, is widely accepted as an indicator of hydration level of the enzyme in non-aqueous enzymology ${ }^{19}$. As shown in Figure 2, the water activity at the level of 0.79 in $n$-heptane gave the maximum initial rate the lipase enzyme activity increased by 2.4 times as compared to the untreated enzyme (un-tuned enzyme) (Table 1). Thus, we observed a drastically reduced reaction time for dehydration process using microwave irradiation in comparison with conventional lyophilization, however in terms of activity enhancement; it was comparable with the results reported by Roy and Gupta ${ }^{20}$, for the lyophilization method.

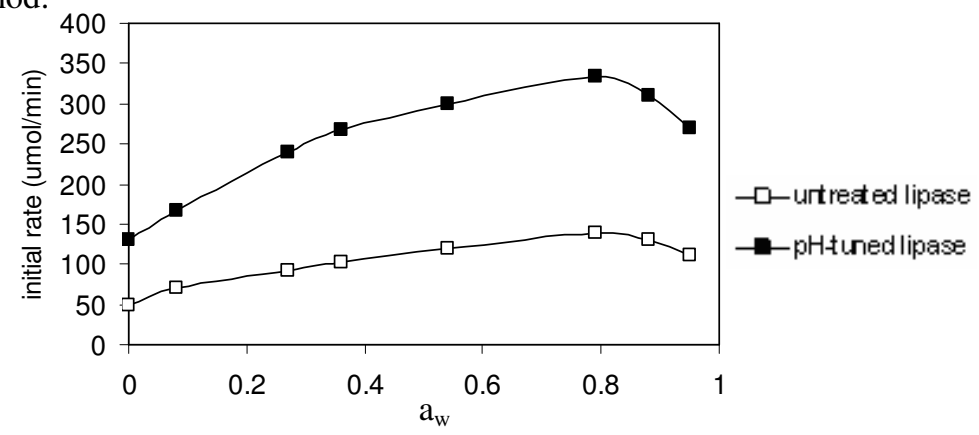

Figure 2. Effect of pH-tuning on the rate of reaction by lipase at various water activities

The two main parameters which are known to affect three phase partitioning are the amounts of ammonium sulphate and $t$-butanol added to the enzyme solution ${ }^{12}$. Previously it was shown that $50 \%(\mathrm{w} / \mathrm{v})$ ammonium sulphate saturation and $6 \mathrm{~mL}$ of $t$-butanol (added to $9.0 \mathrm{mg}$ lipase in $3 \mathrm{~mL}$ of $0.02 \mathrm{M}$ Tris- $\mathrm{HCl}$ buffer, $\mathrm{pH} 7.8$ ) gave 3.2 times increase in the lipase activity in aqueous buffer. It was also shown that the TPP technique using these parameters did not separate significant amount of protein, as only $0.1 \mathrm{mg}$ was left behind in the aqueous layer ${ }^{13}$. Hence in this study similar conditions with slight modification were used for the preparation of TPP-pH tuned lipase enzyme. 
Figure 3 shows the effect of various hydration levels on the activity of untreated and TPP-pH tuned lipase. It is seen that with increasing hydration levels TPP-pH tuned enzyme showed higher reaction rates. Similar to $\mathrm{pH}$-tuned enzyme, the water activity at the level of 0.79 in $n$-heptane gave the maximum initial rate even in the case of TPP-pH-tuned enzyme. The latter showed 3.9 times more activity than the untreated enzyme at this hydration level (Figure 3 and Table 1). The increase in activity of the TPP-pH tuned lipase is because of the increase in inherent catalytic power of the enzyme. TPP-pH tuned treatment can stabilize the structure and molecular flexibility of an enzyme that responsible for the enhancement of enzyme activity ${ }^{12}$. Thus once again, we observe a drastic reduction in time for dehydration process using microwave for the preparation of TPP-pH tuned enzyme.

It was considered worthwhile to examine whether microwave irradiation had any effect on the $\mathrm{pH}$ memory Application of microwave to promote reaction rates of chemical reactions has become fairly routine, but its application in enzyme-catalyzed reactions is relatively limited ${ }^{14}$. Microwave-irradiation is relevant to non-aqueous enzymology because the enzymes in nearly anhydrous media are thermo-stable and in some cases it was reported that keeping them at $100^{\circ} \mathrm{C}$ for an extended period of time does not cause inactivation ${ }^{21}$. This is attributed to the fact that drying removes water molecules which were H-bonded to many surface residues. It results in these side chains interacting with each other and creating a rigid structure. When such powders are used in aqueous buffers, rehydration reverses such changes. On the other hand, when used in low water-containing organic solvents, rehydration is not possible and the structure remains highly thermo-stable. This means that one does not have to worry about thermal inactivation while using microwaves if the medium is nearly anhydrous. Microwave irradiation can be used in conjunction with other strategies for enhancing initial reaction rates. In this study (Figure 3 and Table 1), microwave irradiation on TPP-pH tuned treated lipase resulted in an increase in lipase activity 5.4 times as compared to the rates observed in crude lipase. This study shows that combination of strategies may give a preparation with better catalytic properties

There are two schools of thought about microwave energy transfer to a reaction. One set of research workers believe that microwaves are just a convenient way of heating ${ }^{22}$ while the other group have produced experimental data that point to a non-thermal microwave effect ${ }^{23}$. In the majority of cases the reason for the observed rate enhancements is purely a thermal/kinetic effect, that is, a consequence of the high reaction temperatures that can rapidly be attained when irradiating polar materials in a microwave field. Microwave irradiation triggers heating by two main mechanisms: dipolar polarization and ionic conduction. When irradiated at microwave frequencies, the dipoles or ions of the sample align in the applied electric field. As the applied field oscillates, the dipole or ion field attempts to realign itself with the alternating electric field and, in the process, energy is lost in the form of heat through molecular friction and dielectric loss. Under such conditions, rapid heating of chemical reaction mixtures to high temperatures will be observed ${ }^{24-26}$. Nonthermal effects essentially result from a direct interaction of the electric field with specific molecules in the reaction medium. It has been argued that the presence of an electric field leads to orientation effects of dipolar molecules and hence changes the pre-exponential factor A or the activation energy (entropy term) in the Arrhenius equation. A similar effect should be observed for polar reaction mechanisms, where the polarity is increased going from the ground state to the transition state, thus resulting in an enhancement of reactivity by lowering the activation energy. Microwave effects are the subject of considerable current debate and controversy, and it is evident that extensive research efforts will be necessary to 
truly understand these and related phenomena ${ }^{26-28}$. It is interesting to note, however, that no microwave-assisted reaction is slower than the corresponding conductivity/convectionheated reactions. Not only is direct microwave heating able to reduce chemical reaction times from hours to minutes, but it is also known to reduce side reactions, increase yields, and improve reproducibility ${ }^{27}$. Microwave provides highly focused energy, enabling rapid reaction, substantial savings of energy consumption, and a reduced environmental burden (less $\mathrm{CO}_{2}$ injected into the atmosphere).

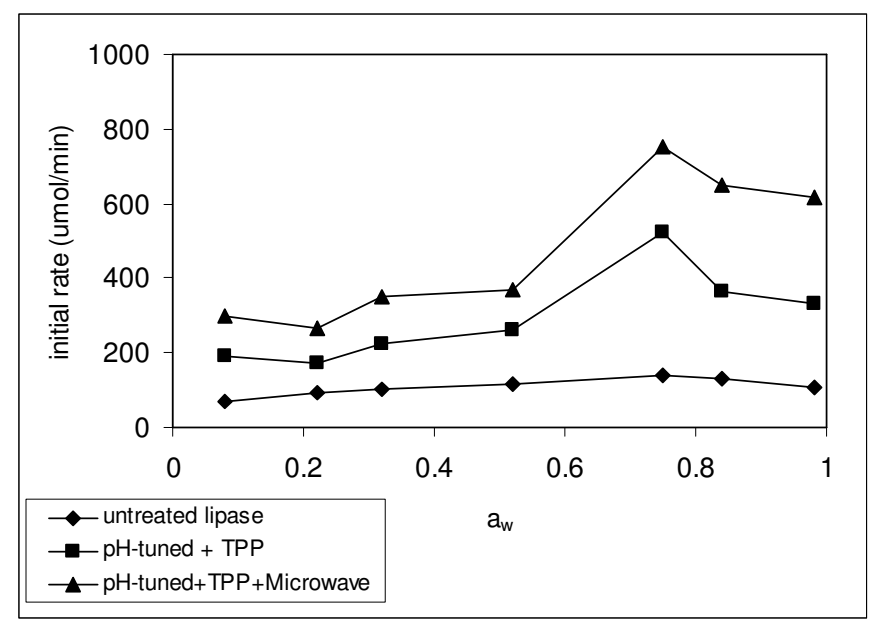

Figure 3. Initial rates of Candida rugosa lipase, untreated, pH-tuned plus TPP-treated and $\mathrm{pH}$-tuned plus TPP treated plus microwave irradiated, at various water activities.

Table 1. Enhancement of lipase activity with pH-tuning, three phase partitioning and microwave irradiation

\begin{tabular}{lcc}
\hline \multicolumn{1}{c}{ Steps } & Activity, units & Increase in Activity, units \\
\hline Crude & 840 & 1 \\
PH- tuned & 1995 & 2.4 \\
pH-tuned plus TPP & 3247 & 3.9 \\
pH-tuned plus TPP and & 4515 & 5.4 \\
microwave irradiation & & \\
\hline
\end{tabular}

\section{Conclusion}

To conclude, the strategy of three phase partitioning can be used in conjunction with addition of microwave irradiation to increase the rates of reaction of lipase in organic media at the right hydration level. The higher initial rates obtained with TPP-treated lipase along with other strategies obviously constitute a more efficient design for catalysis. So far, while individual strategies have been attempted for obtaining more active enzyme preparations for functioning in organic media, this work shows that combination of strategies may give a preparation with considerable enhancement of the enzymatic activity in non-aqueous media. In this study, we have reported the initial results for the enhancement in the performance of an enzyme in non-aqueous media. We will also be studying the effect of immobilization of the microwave irradiated TPP-pH tuned lipase on the transesterification activity for biodiesel production from waste cooking oil. 


\section{References}

1. Chaniotakis N A, Anal Bioanal Chem., 2003, 378, 89-95.

2. Jaeger K E, Dijkstra B W and Reetz M, Annu Rev Microbiol, 1999, 53, 315.

3. Fabricio M G, Ernandes B P and Heizir F D C, Biomacromolecules, 2003, 5, 17-23.

4. Aloulou A, Rodriguez J A, Fernandez S, van Oosterhout D, Puccinelli D and Carriere F, Biochim Biophy Acta, 2006, 1761,995-1013.

5. RCSB Protein Data Bank [http://www.rcsb.org/pdb/home/home.do].

6. Carrea G and Riva S, Angew Chem Int Ed., 2000, 39, 2226-2254.

7. Zaks A and Klibanov A M, J Biochem., 1988, 263, 3194-3201.

8. Griebenow K and Klibanov A M, Proc Natl Acad Sci., USA, 1995, 92,10969-10976.

9. Arakawa T, Prestelski S J, Kenney W C and Carpenter J F, Adv. Drug Deliv. Rev, 2001, 46, 307-326.

10. Lee M Y and Dordick J S, Curr Opin Biotechnol., 2002, 13, 376-384.

11. Gupta M N and Roy I, Eur J Biochem., 2004, 271, 2575-2583.

12. Singh R K, Gourinath S, Sharma S, Roy I, Gupta M N, Betzel C, Srinivasan A and Singh T P, Protein Eng., 2001, 14,307-13.

13. Roy I and Gupta M N, Enzym Microb Tech., 2005, 36, 896-899.

14. Khmelnitsky Y L and Rich J O, Curr Opin Chem Biol., 1999, 3, 47-53.

15. Pencreac'h G and Baratti J C, Enz Microb Technol., 2001, 28, 473-479.

16. Vorderwülbecke T, Kieslich K and Erdmann H, Enz Microb Technol., 1992, 14,631-639.

17. Vulfson E N, Halling P J and Holland H L, Enzymes in Nonaqueous Solvents, Methods and Protocols, 2001, Humana Press, New Jersey.

18. Gupta M N, In: Methods in non-aqueous enzymology, Gupta M N, Editor, Basel: Birkhauser Verlag, 2000, 187-99.

19. Halling P, In: Enzyme catalysis in organic solvents, Drauz K and Waldmann H, Editors. Weinheim: Wiley-VCH; 2002, p 259-85.

20. Roy I and Gupta M N, Tetrahedron, 2003, 59, 5431-5436.

21. Zaks A and Klibanov A M, Science, 1984, 224, 1249-1251.

22. Kuhnert N, Angew Chem Int Ed., 2002, 41, 1863-1866

23. Mayo K G, Nearhoof E H and Kiddle J J, Org Lett., 2002, 4, 1567-1570.

24. Baghurst D R and Mingos D M P, Chem Soc Rev., 1991, 20, 1-47.

25. Gabriel C, Gabriel S, Grant E H, Halstead B S and Mingos, D M P, Chem Soc Rev., 1998, 27, 213-223.

26. Perreux L and Loupy A, Tetrahedron, 2001 57, 9199-9223.

27. Kappe C O, Angew. Chem Int Ed., 2004, 43, 6250-6284.

28. De La Hoz A, Diaz-Ortiz A and Moreno A, Chem Soc Rev., 2005, 34, 164-178. 


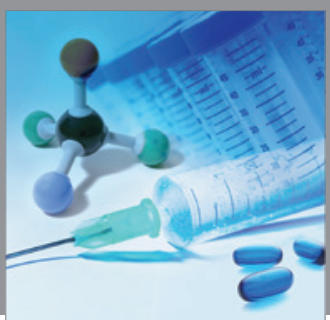

International Journal of

Medicinal Chemistry

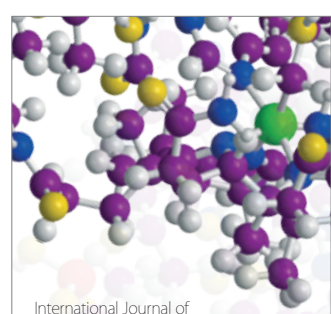

Carbohydrate Chemistry

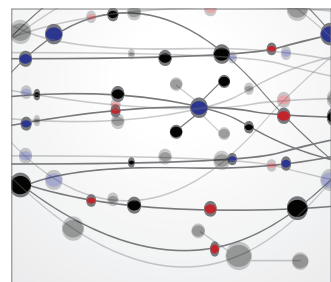

The Scientific World Journal
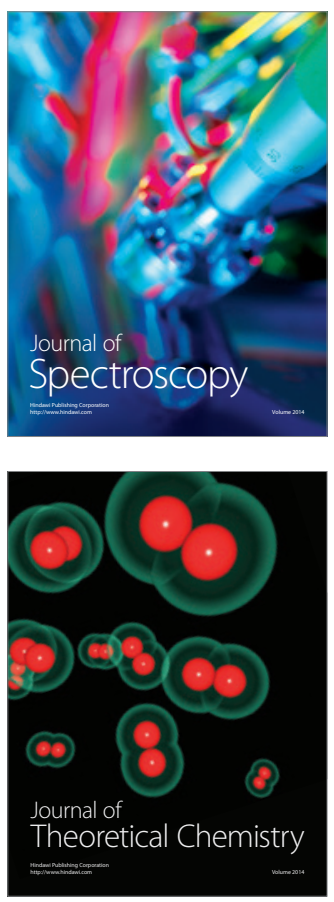
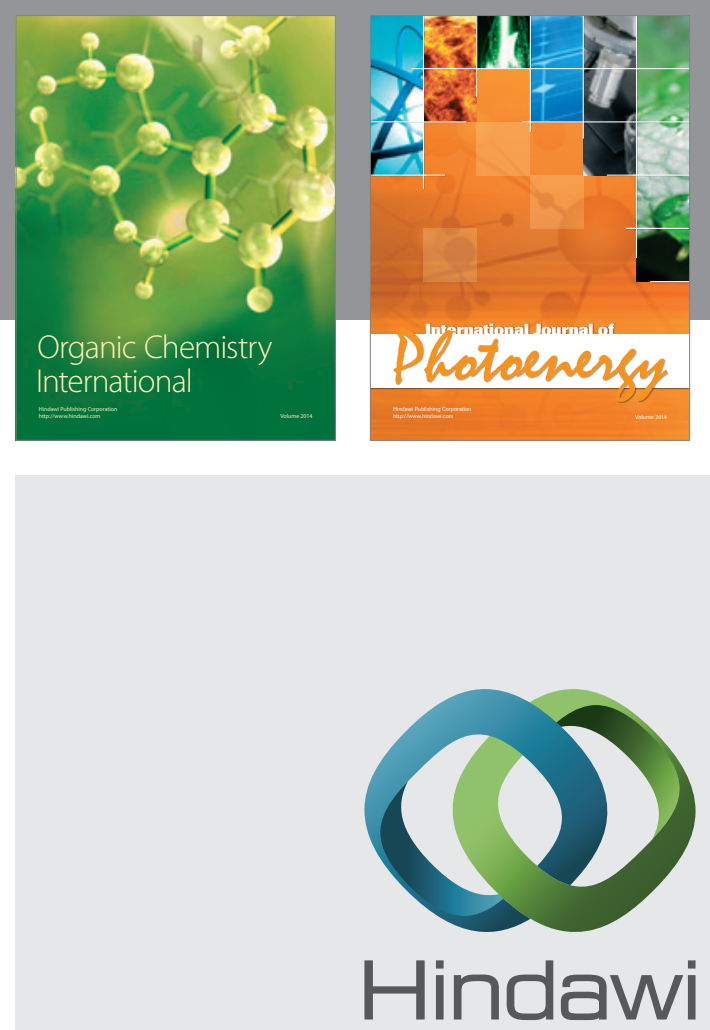

Submit your manuscripts at

http://www.hindawi.com
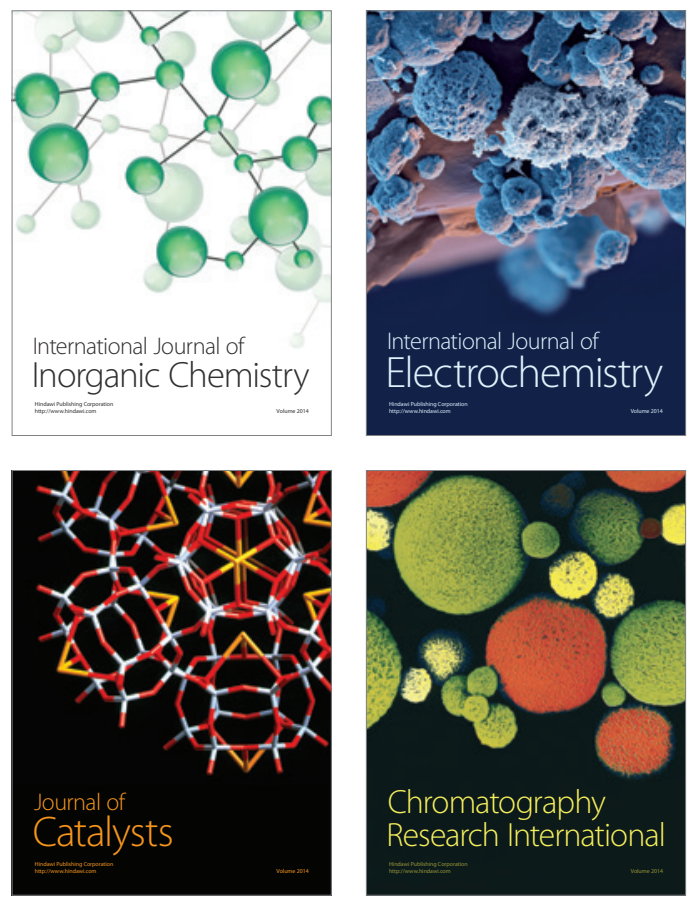
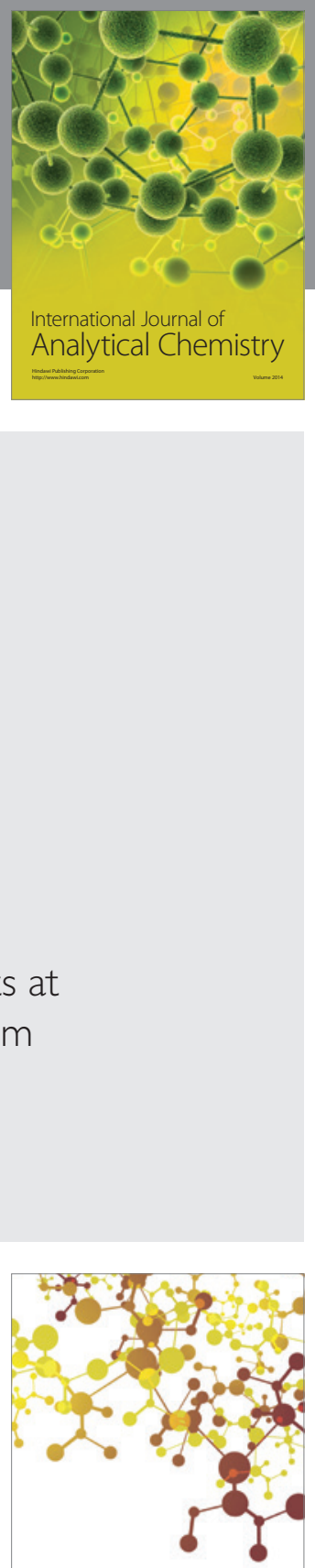

Journal of

Applied Chemistry
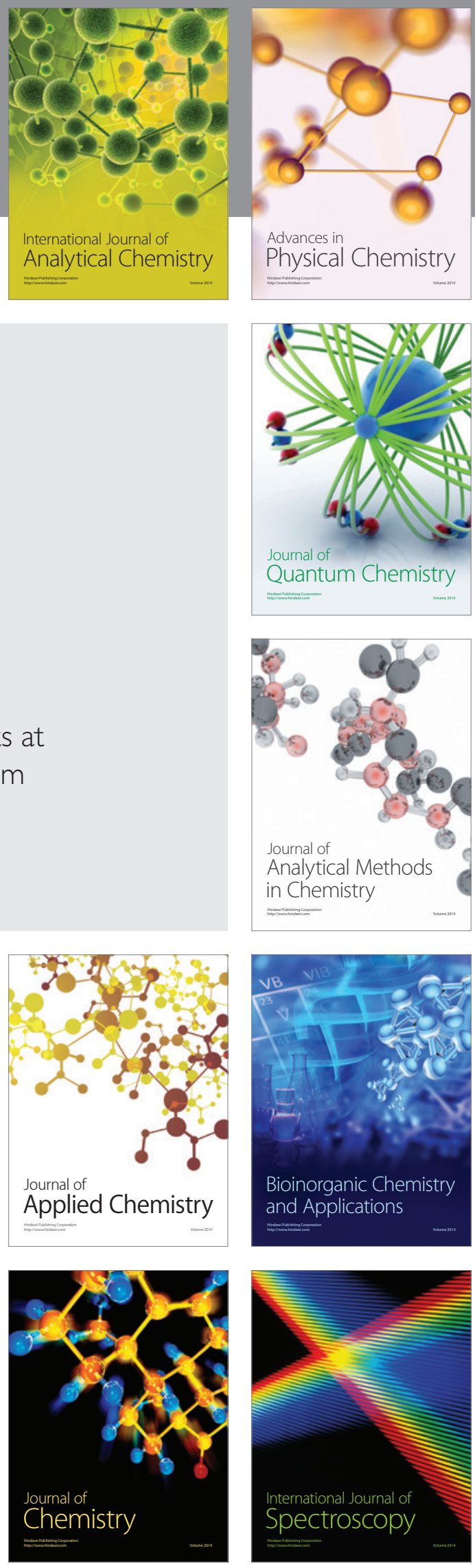